ist ein Bericht zur Probeentnahme mit zwei Durchschriften zu fertigen. Die Originalschrift (weiß) ist als Empfangsbescheinigung bzw. Quittung bestimmt. Die erste Durohschrift (rot) ist der Probebegleitschein. Dieser enthält in der Regel alle für das Untersuchungsamt beachtlichen Angaben und wird mit der Probe diesem zugeleitet. Er wird nach der Untersuchung entweder mit einem Befundvermerk oder unter Beifügung des gutachtlichen Befundberichtes der zuständigen Behörde zurückgesandt. Die zweite Durchschrift (grün) ist als Ausgabebeleg vorgesehen für den Fall, daß der Entschädigungsbetrag nicht bar ausgezahlt, sondern überwiesen wird.

Weiterhin wird das Muster eines Klebeetiketts für Lebensmittelproben in Originalpackungen (Originalbehältnissen) sowie für Bedarfsgegenstände bekanntgegeben. Es wird mit der Nummer des Probebegleitscheins und kurzen Angaben über Art und Herkunft der Probe versehen und auf diese aufgeklebt. Das Klebeetikett auf Flaschen für Milchproben, die einen Konservierungsstoff enthalten, ist durch einen roten Stempelaufdruck , Enthält giftiges Frischhaltemittel" kenntlich zu machen.

Zur Verpackung der Proben von Lebensmitteln, die offen in den Verkehr gebracht werden, sowie zur Verpackung des zurückgebliebenen Teils einer Probe (Gegenprobe) sind Beutel in drei Größen vorgesehen. Zweì davon sind gefüttert und werden dann verwendet, wenn ein Durchfetten oder Durchfeuchten der nicht gefütterten Beutel zu befürchten ist. Auf dem Beutel mit der Gegenprobe sind die gleichen Angaben zu machen, wie auf dem Probebegleitschein.

Das Ergebnis der Probeuntersuchung ist auf einem , Analysenblatts oder in einem Laboratoriumsbuch mit einem Befundvermerk zu protokollieren. Die Analysenblätter sind im Untersuchungsamt laufend numeriert abgeheftet aufzubewahren. Wird die Probe nicht beanstandet, so ist der Probebegleitschein mit dem Vermerk ",Nicht zu beanstanden" der zuständigen Behörde zurückzusenden. Im Falle der Beanstandung ist ein gutachtlicher Bofundbericht zu fertigen und mit dem Probebegleitschein der zuständigen Behörde zuzuleiten. Dem Befundbericht ist in diesem Falle eine Kostenrechnung beizugeben.

$E$. Coduro (München)

\title{
Baden-Württemberg
}

\section{Fleisch und Fleischerzeugnisse}

\section{Ein- und Durchiuhr von Fleiseh, tierisehen Teilen und Erzeugnissen aus dem Ausland}

Verordnung des Innenministeriums von Baden-Wïrtemberg über die Ein- und Durchfuhr von Fleisch, tierischen Teilen und Erzeugnissen sowie Rauhfutter und Stroh aus dem Ausland vom 17. August 1962. - [GBl. für Baden-Württemberg Nr. 14, 185 (1962)]

Verboten ist die Ein- und Durchfuhr von Fleisch von Klauentieren in frischem, gekühltem, gefrorenem, trockenem, gepökeltem, gesalzenem oder geräuchertem Zustand, sonstigen von Klauentieren stammenden Teilen und Erzeugnissen in frischem Zustand, Rauhfutter und Stroh aus Belgien, Frankreich, Italien, Luxemburg, den Niederlanden, Portugal, der Schweiz, Spanien und den Ländern Asiens, Afrikas und Südamerikas, sowie über diese Länder. Als Fleisch gelten auch die aus Klauentieren hergestellten Fette, Fleisch- und Wurstwaren.

Ausgenommen von diesem Verbot ist die Ein- und Durchfahr

1. aus allen Ländern von:

gekochtem Fleisch, Fett, das durch Erhitzen gewonnen ist, Trockenmilch, Trockensabne, kondensierter Sahne in luftdicht verschlossenen Behältnissen und gezuckerter kondensierter Milch in Fässern,

2. aus Luxemburg, den Niederlanden und der Schweiz von:

Fleisch, sofern den Grenzeinlaßstellen durch amtstierärztliche Bescheinigung nachgewiesen wird, daß das Fleisch von Tieren stammt, die während der letzten 30 Tage vor der Schlachtung in einem dieser Länder gestanden haben und vor und nach der Schlachtung in diesen Ländern tier. ärztlich untersucht und gesund befunden worden sind;

3. aus Belgien, Frankreich, Italien, Luxemburg, den Niederlanden, der Sohweiz, Spanien, Portugal, den Ländern Asiens, Südamerikas und Afrikas von:

Geschenksendungen von. Fleisch und im Reiseverkehr mitgeführtem Fleisch bis zum Gesamtgewicht von fünf Kilogramm, Därmen, die vollkommen trocken oder vollkommen gesalzen sind, vollkommen trockenen Hänten und Fellen, vollkommen durchgesalzenen Häuten und Fellen, von Haaren und Fleischteilen befreiten und gekalkten Häuten und Fellen (nassen Blößen) sowie gekalktem Leimleder

$E$. Coduro (München) 